\title{
Community monitoring of the National lodine Deficiency Disorders Control Programme in the National Capital Region of Delhi
}

\author{
Juhi Agarwal ${ }^{1, *}$, Chandrakant S Pandav ${ }^{2}$, Madhukar G Karmarkar ${ }^{3}$ and \\ Sirimavo Nair ${ }^{1}$ \\ 'Department of Foods and Nutrition, Faculty of Family and Community Sciences, The Maharaja Sayajirao \\ University of Baroda, Fatehgunj, Vadodara - 390 002, Gujarat, India: ${ }^{2}$ Centre for Community Medicine, \\ All India Institute of Medical Sciences, New Delhi, India: ${ }^{3}$ Indian Coalition for Control of lodine Deficiency \\ Disorders, c/o Centre for Community Medicine, All India Institute of Medical Sciences, New Delhi, India
}

Submitted 2 June 2009: Accepted 21 January 2010: First published online 1 March 2010

\begin{abstract}
Objective: The present study was conducted to assess the current status of iodinedeficiency disorders (IDD) in the National Capital Region of Delhi (NCR Delhi) and evaluate the implementation and impact of the National Iodine Deficiency Disorders Control Programme (NIDDCP).

Design: Cross-sectional study.

Setting: School-going children ( $n$ 1230) in the age group of 6-12 years were enrolled from thirty primary schools in the Municipal Corporation of Delhi. Thirty schools were selected using the probability-proportional-to-size cluster sampling methodology. In each identified school forty-one children were surveyed. Urine and salt samples were collected and studied for iodine concentration. A total of sixty salt samples from retail level were also collected.

Subjects: Schoolchildren aged 6-12 years.

Results: The median urinary iodine excretion (UIE) was found to be $198 \cdot 4 \mu \mathrm{g} / \mathrm{l}$. The percentage of children with UIE levels of $<20 \cdot 0,20 \cdot 0-49 \cdot 9,50 \cdot 0-99 \cdot 9$ and $\geq 100 \cdot 0 \mu \mathrm{g} / \mathrm{l}$ was $1 \cdot 9,4 \cdot 3,9 \cdot 5$ and $84 \cdot 2 \%$, respectively. The proportion of households consuming adequately iodized salt (salt with iodine levels of at least $15 \mathrm{ppm}$ at consumption level) was $88 \cdot 8 \%$. The assessment of iodine content of salt revealed that only $6 \cdot 1 \%$ of the families were consuming salt with iodine content less than $7 \mathrm{ppm}$. At retail level $88 \cdot 3 \%$ of salt samples had $>15 \mathrm{ppm}$ iodine. Conclusions: Significant progress has been achieved towards elimination of IDD from NCR Delhi. There is a need for further strengthening of the system to monitor the quality of iodized salt provided to the beneficiaries under the universal salt iodization programme and so eliminate IDD from NCR Delhi.
\end{abstract}

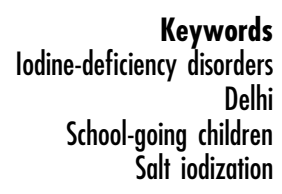

Malnutrition remains a major risk limiting the development potential and active learning capacity of India's children. Every second newborn in India is at risk of reduced learning capacity due to iodine deficiency. Thus the elimination of iodine deficiency is an important social and developmental goal which could have a far-reaching impact on economic growth. The best and most costeffective way to achieve this aim as far as India is concerned is to use iodized salt.

Iodine taken in the diet is converted into iodide before it is absorbed into the bloodstream through the gastrointestinal tract. Over $90 \%$ of the body's iodine is excreted in the urine; thus urinary iodine concentration is the best index for the assessment of iodine nutriture and is a good indicator of very recent dietary intake ${ }^{(1,2)}$. The cut-off values to define a population with no iodine deficiency ${ }^{(2)}$ are: median urinary iodine concentrations between 100 and $299 \mu \mathrm{g} / \mathrm{l}$ in children; and between 150 and $249 \mu \mathrm{g} / \mathrm{l}$ in pregnant women. In addition, not more than $20 \%$ of the samples within a given population should have median urinary iodine concentrations less than $50 \mu \mathrm{g} / \mathrm{l}$. According to $\mathrm{WHO}$, community indicators can be classified in the following manner: median urinary iodine concentrations $<20 \cdot 0,20 \cdot 0-49 \cdot 9$ and 50.0-99.9 $\mu \mathrm{g} / 1$ show severe, moderate and mild iodine deficiency, respectively, in schoolage children.

Iodine deficiency causes a spectrum of diseases called iodine-deficiency disorders (IDD) ${ }^{(3)}$, which include goitre, cretinism, spontaneous abortion, still birth, birth defects, defects of speech and hearing, squint and psychomotor 
defects. Indeed, IDD is the only cause of preventable mental handicap worldwide. In man, $90 \%$ of the capacity of an adult brain is acquired in the last six months of gestation and the first three years of life ${ }^{(4)}$. During this period iodine deficiency leads to impaired synthesis of thyroid hormones by the mother and fetus, which can induce irreversible brain damage of the fetus and young infant. A meta-analysis of studies carried out in twenty different countries found that the IQ (Intelligence Quotient) score of children living in an iodine-deficient environment is nearly 13 points less than that of children living in iodine-sufficient environments ${ }^{(5)}$. Severe iodine deficiency leads to high number of individuals referred to as endemic cretins ${ }^{(6)}$.

Iodine deficiency is one of the most important micronutrient deficiencies globally. About 1.5 billion people worldwide live at risk of IDD, of whom more than 655 million people are already affected by IDD. In India, about 150 million people are exposed to the risk of IDD, whereas more than 71 million people are suffering from goitre and other $\operatorname{IDD}^{(7,8)}$. Universal salt iodization (USI) is the principal public health measure for eliminating IDD, since it covers all classes of living. In the National Capital Region of Delhi (NCR Delhi) several studies on IDD have been conducted since $1982^{(9)}$.

A study carried out in 1997 among schoolchildren of Delhi showed that IDD continued to be prevalent in mildly endemic proportions. The total goitre prevalence rate was $19 \cdot 7 \%$, while $23.6 \%$ of children had urinary iodine excretion (UIE) below $100 \mu \mathrm{g} / 1$ and $7 \cdot 6 \%$ had no iodine in their urine ${ }^{(10)}$.

The findings of a study conducted in the year 2002 in NCR Delhi indicated that the population was in a transition phase from iodine-deficient (as revealed by total goitre prevalence of $6 \cdot 2 \%)$ to iodine-sufficient nutriture ${ }^{(11)}$.

In light of the above mentioned situation, the present study was conducted with the following objectives:

1. to evaluate the implementation and impact of the National Iodine Deficiency Disorder Control Programme (NIDDCP);

2. to assess the current status of IDD in Delhi using criteria from WHO/UNICEF/International Council for the Control of Iodine Deficiency Disorders (ICCIDD);

3. to measure the condition or progress in implementing the NIDDCP by measuring salt iodine levels.

\section{Materials and methods}

The study was undertaken in the year 2007 in NCR Delhi. In Delhi, the school enrolment of children in primary classes was more than $90 \%$ and hence the school approach was adopted.

The EPI-30 cluster sampling methodology as recommended by the Joint WHO/UNICEF/ICCIDD consultation was followed ${ }^{(12)}$. As per the recommendation of WHO/ UNICEF/ICCIDD, schoolchildren in the age group 6-12 years of both sexes were selected ${ }^{(1)}$. A sample size of 1230 children was taken from thirty primary schools in the Municipal Corporation of Delhi. Thirty schools (clusters) were selected using the probability-proportional-to-size cluster sampling methodology ${ }^{(12)}$. In each identified school forty-one children in the age group of 6-12 years were surveyed. Children were briefed about the objectives of the study during the morning assembly. The consent of the principal of each school was obtained through Delhi State Bharat Scouts and Guides. Consent from students who were enrolled for the study was also obtained. All children included in the study were provided with auto-seal polythene pouches and plastic bottles with screw caps with an identification slip for collecting urine samples.

The children were requested to bring four teaspoons of salt (about $20 \mathrm{~g}$ ) from their home in the pouch. The iodine content of the salt samples was analysed using the standard iodometric titration method ${ }^{(13)}$. An internal quality control sample having a known concentration range of iodine content was run with every batch of test samples. If the results of the internal quality control sample were within the range, the test was deemed in control and if the results were outside the range, the whole batch was repeated.

The children were requested to provide a casual urine sample in the screw-capped plastic bottle during school time. The samples were transferred to vials and stored in a refrigerator until analysis. The UIE levels were analysed using the simple microplate method ${ }^{(14)}$. An internal quality control sample having a known concentration range of iodine content was run with every batch of test samples. If the results of the internal quality control sample were within the range, the test was deemed in control and if the results were outside the range, the whole batch was repeated.

\section{Results}

A total of 1230 children aged between 6 and 12 years were studied. The BMI of the children ranged from $14 \cdot 0$ to $24 \cdot 8 \mathrm{~kg} / \mathrm{m}^{2}$. There were $678(55 \cdot 1 \%)$ girls and 552 (44.9\%) boys.

\section{Urinary iodine excretion}

A total of 1230 urine samples were collected and analysed for iodine content. The median UIE was found to be $198.4 \mu \mathrm{g} / \mathrm{l}$. Approximately $6.3 \%$ of the values were $<50 \mu \mathrm{g} / \mathrm{l}, 15 \cdot 9 \%$ of the values were $<100 \mu \mathrm{g} / \mathrm{l}$ and $84 \cdot 2 \%$ of the values were $\geq 100 \mu \mathrm{g} / \mathrm{l}$ (Fig. 1).

\section{Iodine content of salt at housebold level}

A total of 1230 salt samples were analysed. The proportion of households consuming adequately iodized salt 


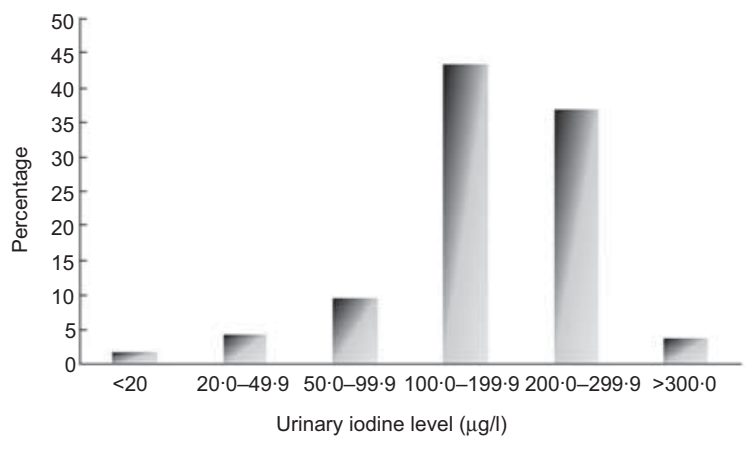

Fig. 1 Distribution of urinary iodine excretion values in the study population: school-going children ( $n$ 1230) aged 6-12 years, Delhi, 2007

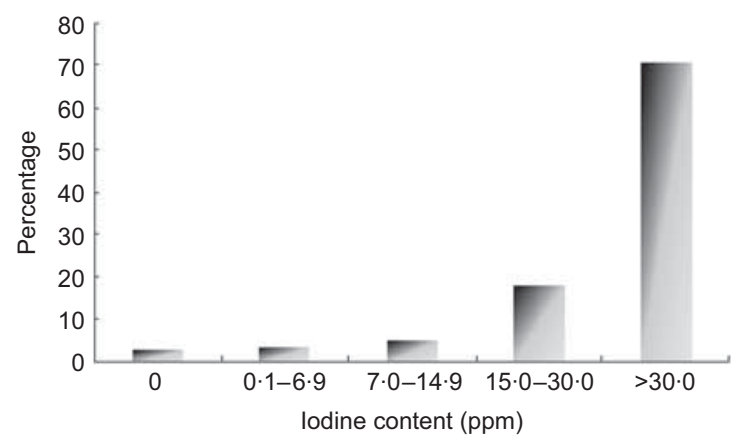

Fig. 2 Distribution of iodine content of salt at household level (n 1230), Delhi, 2007

(salt with iodine levels of at least $15 \mathrm{ppm}$ at consumption level) was $88 \cdot 8 \%$ (Fig. 2).

\section{Iodine content of salt at retail level}

A total of sixty salt samples across different salt types (crystal, powdered and refined) were collected from the thirty clusters. Of these, four (6.7\%) samples had less than $7 \mathrm{ppm}$ iodine. Another three $(5 \cdot 0 \%)$ samples had iodine content between 7 and $14.9 \mathrm{ppm}$. In the remaining fifty-three $(88 \cdot 3 \%)$ samples, iodine content was $15 \mathrm{ppm}$ or more (Fig. 3).

\section{Discussion}

Iodine deficiency has been recognized as a public health problem in India and regular consumption of iodized salt was demonstrated as an effective strategy for goitre prevention and control ${ }^{(15)}$.

Salt is consumed at approximately the same level every day throughout the year by the population. The average intake of salt per person per day in India is approximately $10 \mathrm{~g}$. With the addition of $15 \mathrm{mg}$ of iodine to $1 \mathrm{~kg}$ of salt $(15 \mathrm{ppm})$, a person would receive $150 \mu \mathrm{g}$ of iodine daily. This is dependent on the efficiency of the mixing procedure and the stability of iodine in salt during transportation and storage. Thus, a micronutrient like

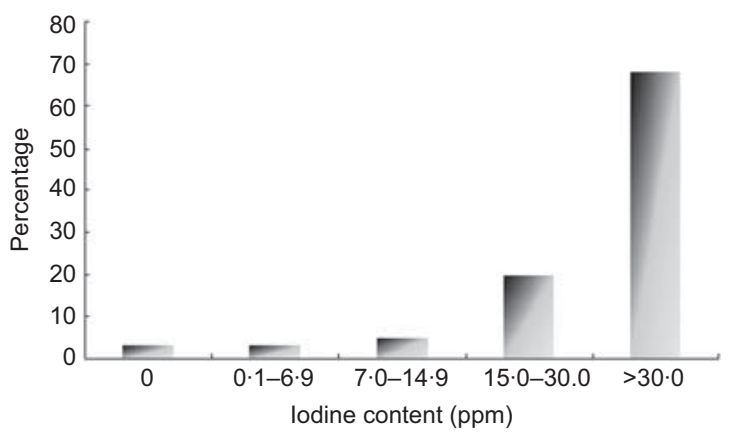

Fig. 3 Distribution of iodine content of salt at retail level ( $n 60)$, Delhi, 2007

iodine can be introduced through salt at a uniform dosage every day ${ }^{(16)}$.

The criteria for monitoring progress towards elimination of IDD as a public health problem are based on UIE patterns and iodine levels in salt. Based on the standard recommendations, the proportion of people having UIE below $100 \mu \mathrm{g} / \mathrm{l}$ and below $50 \mu \mathrm{g} / \mathrm{l}$ should be $<50 \%$ and $<20 \%$, respectively, and the proportion of households consuming adequately iodized salt should be $>90 \%{ }^{(2)}$.

Based on the above criteria in the present study we found the following: median UIE in the children studied in the age group $6-12$ years was $198 \cdot 4 \mu \mathrm{g} / 1$, with $6 \cdot 3 \%$ of the population having UIE $<50 \mu \mathrm{g} / \mathrm{l}$. These results are quite encouraging, as they show a reduction of approximately $7 \cdot 7 \%$ in the proportion of children having UIE $<100 \mu \mathrm{g} / 1$ from 1997 to 2007 . Adequate iodine intake was present in $88.8 \%$ of the households. Compared with other studies, this also indicates an improvement in IDD status in children. However, further efforts should be made to increase the proportion of households consuming adequately iodized salt to $>90 \%$. Similar results were observed by Bhat et al., suggesting the transition from deficient iodine nutriture to sufficient levels in six districts of Jammu ${ }^{(17)}$.

In our study, a 'child to community' approach was used by involving the children to create more awareness and demand for iodized salt. Testing the iodine content of salt through a school-based approach proved very effective in terms of monitoring the progress in availability and consumption patterns in the state. The results obtained from school data on the availability of the salt were concurrent with the fact and findings of an external evaluation carried out in December $2005^{(18)}$. Similar observations have been reported by Vir et al. ${ }^{(19)}$.

Hence we propose that, with improved reach and coverage of iodized salt and sustained efforts to increase awareness, IDD can be virtually eliminated. This can be achieved in the following ways:

- educating or making children aware that they should consume iodized salt to prevent possible loss of learning capability; 
- include iodine nutrition in the school curriculum so that children are aware of it;

- hold regular seminars or programmes to highlight the use of adequately iodized salt by all in schools.

There is a need for further strengthening the system of monitoring the quality of iodized salt provided to beneficiaries under the USI programme, to eliminate IDD from NCR Delhi. Our results at retail level revealed that $88 \cdot 3 \%$ of the salt was adequately iodized at varying levels (ppm). Recommendations and suggestions to improve this situation include the following.

1. Technical support for best utility of potassium iodate should be propagated for small-scale salt traders ${ }^{(20)}$.

2. Constant monitoring and periodic review has been shown to enhance the production of quality iodized salt (K Joshi and S Nair, unpublished results). Hence effective monitoring is a suggestive measure to improve iodized salt production and consumption.

\section{Acknowledgements}

Source of funding: Indian Council of Medical Research, New Delhi, India. Conflict of interest declaration: The authors declare that they have no conflict regarding this paper and have had no involvements that might raise the question of bias in the work reported or in the conclusions, implications and opinions stated. Authorship responsibilities: All of the authors listed on this paper meet the criteria set down by the International Committee of Medical Journal Editors. All authors were involved in the setup of the study, in the study itself and writing of the paper. No one who might consider that he or she has a right to be an author has been excluded. Acknowledgements: We thank the Indian Council of Medical Research for providing the financial assistance and Bharat Scouts and Guides for their support, cooperation and providing technical assistance in carrying out the research work.

\section{References}

1. Dunn JT, Crutchfield HE, Gutekunst R et al. (1993) Methods for Measuring Iodine in Urine. ICCIDD/UNICEF/WHO Publication. Wageningen: International Council for the Control of Iodine Deficiency Disorders.

2. World Health Organization/UNICEF/International Council for the Control of Iodine Deficiency Disorders (2007)
Assessment of Iodine Deficiency Disorders and Monitoring Their Elimination: A Guide for Programme Managers, 3rd ed. Geneva: WHO.

3. Hetzel BS (1983) Iodine deficiency disorders and their eradication. Lancet ii, 1126-1129.

4. Delong JT \& Stanbury JB (editors) (1987) The Prevention of Iodine Deficiency Disorders, pp. 49-64. Amsterdam: Elsevier Science Publishers.

5. Bleichrodt N \& Born MP (1994) A meta-analysis of research on iodine and its relationship to cognitive development. In The Damaged Brain of Iodine Deficiency - Cognitive Behavioral, Neuromotor and Educative Aspects, pp. 195-200 [JB Stanbury, editor]. New York: Cognizant Communication Corporation.

6. Glinoer D (2001) Pregnancy and iodine. Thyroid 11, 471-481.

7. de Benoist B, McLean E, Andersson M et al. (2008) Iodine deficiency in 2007: global progress since 2003. Food Nutr Bull 29, 195-202.

8. Excelsior-Nation (2004) 71 million people suffer from iodine deficiency in India. http://www.dailyexcelsior.com/ web1/04feb27/national.htm\#3 (accessed February 2004)

9. Pandav CS, Kochupillai N, Karmarkar MG et al. (1982) Endemic goiter in Delhi. Indian J Med Res 72, 81-88.

10. Pandav CS, Mallik A, Anand K et al. (1997) Prevalence of iodine deficiency disorders among school children of Delhi. Natl Med J India 10, 112-114.

11. Kapil U, Sethi V, Goindi G et al. (2004) Elimination of iodine deficiency disorders in Delhi. Indian J Pediatr $\mathbf{7 1}$, 211-212.

12. Lemeshow S, Hosmer DW Jr, Klar J et al. (1990) Adequacy of Sample Size in Health Studies. Chichester: John Wiley \& Sons.

13. Tyabji R, Karmarkar MG, Pandav CS et al. (1990) Estimation of iodine content in iodated salt. In A Hand Book of Monitoring and Quality Control, pp. 18-32. New Delhi: UNICEF/ROSCA.

14. Ohashi T, Yamaki M, Pandav CS et al. (2000) Simple microplate method for determination of urinary iodine. Clin Chem 46, 529-536.

15. Sooch SS, Deo MG, Karmarkar MG et al. (1973) Prevention of endemic goiter with iodized salt. Bull World Health Organ 49, 307-312.

16. Mannar MVG \& Dunn JT (1995) Salt Iodization for the Elimination of Iodine Deficiency. ICCIDD/MI/UNICEF/ WHO Publication. Wageningen: International Council for the Control of Iodine Deficiency Disorders.

17. Bhat IA, Pandit MI \& Mudassar S (2008) Study on prevalence of iodine deficiency disorder and salt consumption patterns in Jammu region. Indian J Community Med 33, 11-14.

18. National Rural Health Mission, Government of India (2005) Coverage and Evaluation Survey, All India Report. Delhi: National Rural Health Mission.

19. Vir SC, Dwivedi S, Singh R et al. (2007) Reaching the goal of universal salt iodization (USI): experience of Uttar Pradesh, India. Food Nutr Bull 28, 384-390.

20. Nair S \& Joshi S (2006) Consultancy and Technical Report to UNICEF-Gujarat. Gandhinagar, Gujarat: UNICEF. 